\title{
PERFIL AUDIOLÓGICO DE IDOSOS ATIVOS
}

Carla Vanessa Jardim da Silveira; Universidade Federal do Rio Grande do Sul; carlajsilveira@hotmail.com Adriane Ribeiro Teixeira; Universidade Federal do Rio Grande do Sul e Hospital de Clínicas de Porto Alegre; adriane.teixeira@gmail.com

\section{RESUMO}

Introdução: $\mathrm{O}$ envelhecimento ativo pressupõe a participação nas atividades sociais, culturais e econômicas. Os idosos com presbiacusia podem apresentar dificuldade em se comunicar, e isso pode limitar ou incapacitar os sujeitos. Objetivo: Analisar perfil audiológico de idosos ativos. Métodos: Estudo transversal, realizado com idosos matriculados nas atividades de extensão na universidade. Critério de inclusão: indivíduos com capacidade de responder a audiometria tonal liminar. Critérios de exclusão: não completar a avaliação ou com cera obstrutiva no conduto auditivo externo. Todos passaram por inspeção do conduto auditivo externo e audiometria tonal liminar (realizada em cabina acustica). A análise da presença e do grau de perda auditiva foi considerada a classificação da Organização Mundial da Saúde. Os resultados foram analisados de forma quantitativa, com o cálculo de valores absolutos e relativos. O estudo foi aprovado por comitê de ética. Resultados: A amostra foi de 129 idosos, 86\% do sexo feminino. A média de idade foi de 65,5 anos. Em ambas as orelhas a maior prevalência foi de perda auditiva neurossensorial (76,7\%). Na orelha direita, $23,3 \%$ apresentaram limiares auditivos normais, $26,4 \%$ perda leve, $10,1 \%$ perda moderada e $40,3 \%$ perda limitada às frequências altas. Na orelha esquerda constatou-se $23,3 \%$ com limiares auditivos normais, $26,4 \%$ com perda leve, $10,1 \%$ com perda moderada e $43,2 \%$ com perda auditiva limitada às frequências altas Conclusão: Constatou-se que a presença de perda auditiva foi elevada na amostra avaliada. Assim, sugere-se que em programas para idosos a avaliação audiológica possa ser incluída dentre o rol de avaliações.

Palavras-chave: Perda Auditiva; Envelhecimento; Presbiacusia. 